\title{
Właściwości mechaniczne niejednorodnego złącza spawanego stali VM12/X20 po wyżarzaniu
}

\author{
Mechanical properties of heterogeneous \\ welded joint steels VM12/X20 after annealing
}

\section{Streszczenie}

Badaniu poddano niejednorodne złącza spawane martenzytycznych stali VM12/X20CrMoV12-1 (X20) łączone dwoma różnymi materiałami dodatkowymi. Do wypełnienia pierwszego ściegu (grani) zastosowano materiał dodatkowy przeznaczony dla stali X20, kolejne ściegi, włącznie z licowym, wykonano materiałem dodatkowym dla stali VM12. Na uzyskanych złączach przeprowadzono nieniszczące i niszczące badania ich jakości, które wykazały prawidłową budowę złączy bez niezgodności spawalniczych. Wyżarzanie złącza stali VM12/X20 w temperaturze $770{ }^{\circ} \mathrm{C}$ przez jedną godzinę pozwala na uzyskanie zbliżonych do pożądanych właściwości mechanicznych (wytrzymałości na rozciąganie, kąta gięcia i udarności) oraz twardości złącza na akceptowalnym poziomie ok. 320 HV10. Dłuższe czasy wyżarzania prowadzą do obniżenia zarówno udarności złącza, a w szczególności spoiny oraz wytrzymałości na rozciąganie. Jednocześnie twardość złącza ulega obniżeniu do wartości odpowiadającej twardości materiałów rodzimych, tj. stali VM12 i X20. Wykazano, że złącza tego typu umożliwiają uzyskanie właściwie pracujących zespołów roboczych w remontowanych instalacjach energetycznych.

Słowa kluczowe: złącza niejednorodne, właściwości mechaniczne

\section{Abstract}

The study was heterogeneous welded joints VM12/ X20CrMoV12-1 (X20) martensitic steel used two different additional materials: the first pass - consumable dedicated for X20 steels, the following passes including face pass - consumable for VM12 steel. On the resulting joints are made non-destructive and destructive testing of the quality, which validated the correct joints structure and the absence of welding defects. Annealing joint VM12/X20 steel at a temperature of $770{ }^{\circ} \mathrm{C}$ for one hour allows to obtain similar to the desired mechanical properties (tensile strength, bending angle and impact resistance) and the hardness of the joint on the acceptable level of approx. $320 \mathrm{HV} 10$. Longer annealing times lead to a reduction in toughness of both joints and in particular the tensile strength. At the same time the hardness of the joint is reduced to the hardness of the material that is native, i.e. VM12 and X20 steel. It was shown that joints of this type can produce valid working systems in repaired power plant facilities.

Keywords: heterogeneous welded joints, mechanical properties

\section{Wstęp}

Ograniczenia związane z emisją zanieczyszczeń do atmosfery $\mathrm{w}$ wyniku spalania paliw kopalnych $w$ energetyce wymagają nie tylko budowy nowych, ale również modernizacji starych bloków energetycznych celem uzyskania możliwości pracy przy tzw. parametrach nadkrytycznych pary. Podczas modernizacji elementów instalacji bloków zachodzi konieczność łączenia między sobą stali żarowytrzymałych różnych gatunków i generacji $[1 \div 3]$. Stwarzać to może szereg problemów natury technologicznej, do których zaliczyć należy m.in. dobór materiału dodatkowego do spawania, dobór parametrów obróbki cieplnej złączy po spawaniu czy też dyfuzję reaktywną węgla

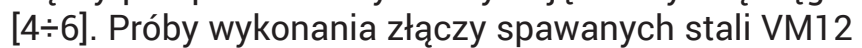
i X20CrMoV12-1 (X20) na przegrzewaczach pary w bloku o mocy $460 \mathrm{MW}$ wykazały trudności w trakcie wykonywania pierwszego ściegu graniowego, co powodowało powstawanie mikropęknięć, pęknięć i porowatości [7]. Z tego względu zaproponowano wykonanie pierwszego ściegu innym niż materiał rodzimy (stal VM12) materiałem dodatkowym, tj. materiałem przeznaczonym dla stali X20.

Mgr inż. Joanna Jasak, dr inż. Kwiryn Wojsyk, dr hab. inż. Grzegorz Golański- Politechnika Częstochowska. 
Głównym celem pracy była ocena jakości wykonanego złącza VM12/X20 łączonego dwoma różnymi materiałami dodatkowymi oraz określenie wpływu czasu wyżarzania w temperaturze $770^{\circ} \mathrm{C}$ na właściwości mechaniczne złącza stali VM12/X20.

\section{Materiał i metodyka badań}

Materiałem do badań było niejednorodne złącze spawane stali VM12 i X20CrMoV12-1 (X20). Złącze spawane stali VM12/X20 wykonane zostało w następujący sposób: pierwszy ścieg (grań) wykonano materiałem dodatkowym W CrMoWV12Si (W1) przeznaczonym dla stali X20CrMoV12-1, natomiast kolejne ściegi, włącznie z licowym, materiałem dodatkowym W ZCrCoW 1122 (W2) dla stali VM12. Wykonane złącza oraz ich parametry obróbki cieplnej po spawaniu zestawiono w tablicy l. Złącza zespawano metodą TIG (141), używając jako gazu ochronnego argonu (11), a jako gazu formującego mieszankę H2/N2 (F2). Przed spawaniem styk podgrzano do temperatury ok. $200^{\circ} \mathrm{C}$. W trakcie spawania temperatura międzyściegowa nie przekraczała $280^{\circ} \mathrm{C}$.

W celu oceny prawidłowości wykonanych złączy spawanych zostały one poddane badaniom: nieniszczącym - wizualnym (VT) i radiograficznym (RT) w zakresie $100 \%$ z uwzględnieniem poziomu jakości B wg PN-EN ISO 5817, metalograficznym oraz badaniom właściwości mechanicznych. Badania mikrostrukturalne niejednorodnych złączy spawanych wykonano za pomocą mikroskopu świetlnego Axiovert 25. Obserwację i rejestrację mikrostruktur przeprowadzono na przygotowanych zgładach metalograficznych, trawionych odczynnikiem metalograficznym - $\mathrm{FeCl}_{3}$. Zakres przeprowadzonych badań mechanicznych obejmował: pomiar twardości metodą Vickersa przy obciążeniu 98,1 N (10 kG), statyczną próbę rozciągania oraz próbę zginania na próbkach płaskich. Do gięcia zastosowano trzpień o średnicy $18,9 \mathrm{~mm}(3 \mathrm{~g})$ przez co kryterium oceny zostało zaostrzone. Kryterium pozytywnym tej próby było uzyskanie kąta gięcia $180^{\circ}$ bez wystąpienia rys i pęknięć na rozciąganej powierzchni próbki. Próbę udarności przeprowadzono $w$ temperaturze pokojowej, stosując niestandardowe próbki typu Charpy V o przekroju 10x6,3 mm. Badania właściwości mechanicznych przeprowadzono według obowiązujących norm.

\section{Badania nieniszczące i metalograficzne}

Przeprowadzone badania nieniszczące wykazały, że analizowane złącza charakteryzują się wymaganym poziomem jakości. Przykładowe makroskopowe obrazy badanych złączy przedstawiono na rysunku 1.
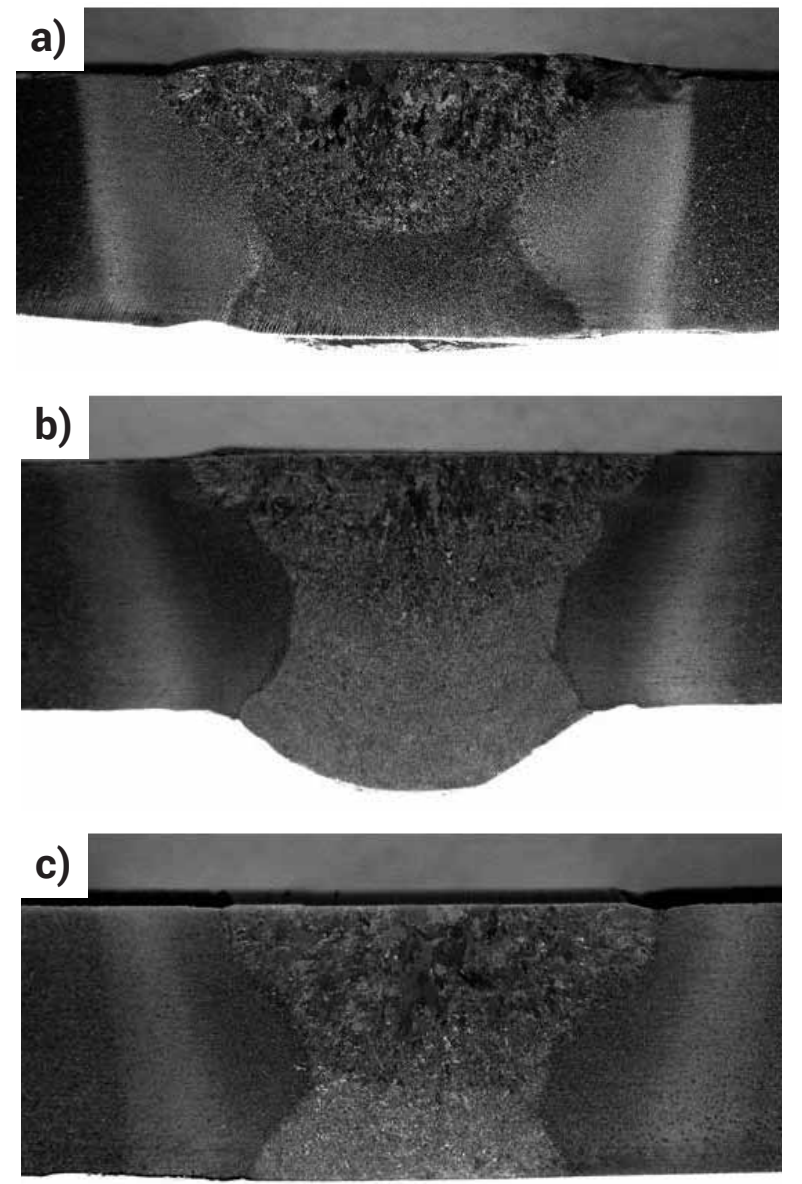

Rys. 1. Makroskopowy obraz badanych złączy: a) złącze Nr 8, b) złącze $\mathrm{Nr} 11$, c) złącze $\mathrm{Nr} 17$

Fig. 1. The view of joint cross-sections: a) joint No. 8, b) joint No. 11, c) joint No. 17

Badania makroskopowe na przekrojach złączy nie ujawniły obecności pęknięć i nieciągłości oraz potwierdziły prawidłową budowę poszczególnych stref niejednorodnego złącza spawanego stali VM12/X20 bez istotnych niezgodności spawalniczych. Kształt spoiny i układ ściegów był prawidłowy. Badania mikrostrukturalne nie wykazały obecności obszarów o nieprawidłowej budowie. Złącza charakteryzowały się mikrostrukturą martenzytu odpuszczonego (rys. 2).

Tablica I. Zestawienie zbiorcze wykonanych złączy spawanych Table I. The summary of analyzed weld joints

\begin{tabular}{|c|c|c|c|c|c|}
\hline \multirow{2}{*}{ Nr złącza } & \multirow{2}{*}{$\begin{array}{c}\text { Wymiary } \\
\text { złącza }\end{array}$} & \multicolumn{2}{|c|}{ Materiał dodatkowy do spawania } & \multirow{2}{*}{$\begin{array}{c}\text { Temperatura } \\
\text { obróbki cieplnej, }{ }^{\circ} \text { C }\end{array}$} & $\begin{array}{c}\text { Czas } \\
\text { obróbki cieplnej, h }\end{array}$ \\
\cline { 3 - 6 } & $\varnothing 44,5 \times 6,3$ & Przetop - grań & Wypełnienie i lico & - & - \\
\hline 8 & $\varnothing 44,5 \times 6,3$ & W CrMoWV12Si & W ZCrCoW 1122 & 770 & 1 \\
\hline 11 & $\varnothing 44,5 \times 6,3$ & W CrMoWV12Si & W ZCrCoW 1122 & 770 & 24 \\
\hline 15 & $\varnothing 44,5 \times 6,3$ & W CrMoWV12Si & W ZCrCoW 1122 & 770 & 48 \\
\hline 16 & $\varnothing 44,5 \times 6,3$ & W CrMoWV12Si & W ZCrCoW 1122 & 770 & 72 \\
\hline
\end{tabular}



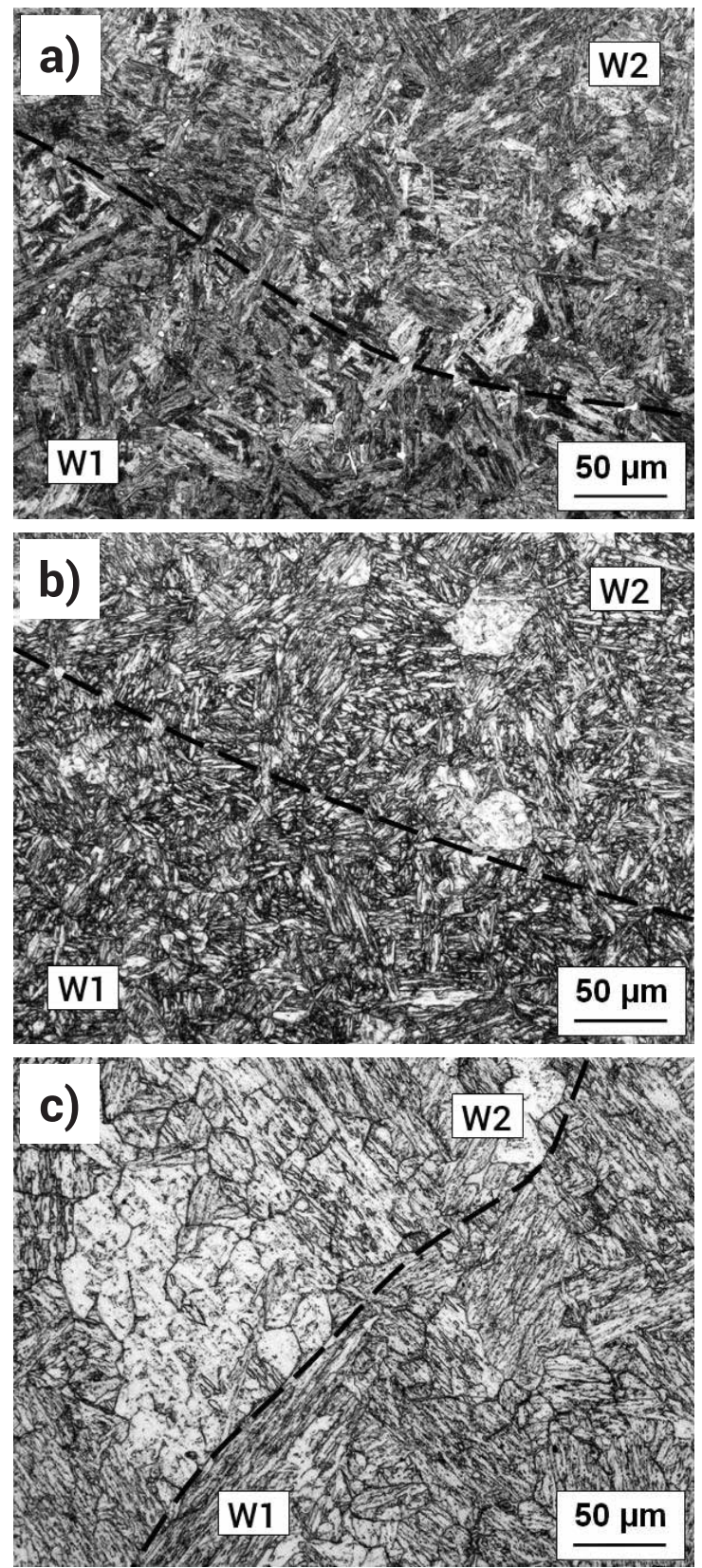

Rys. 2. Mikrostruktura spoiny: a) złącze $\mathrm{Nr} 8$; b) złącze $\mathrm{Nr} 11$, c) złącze $\mathrm{Nr} 17, \mathrm{OM}$, traw. $\mathrm{FeCl}_{3}$

Fig. 2. Microstructure of weld: a) joint No. 8; b) joint No. 11, c) joint No. 17, $\mathrm{OM}, \mathrm{FeCl}_{3}$ etched

\section{Badania właściwości mechanicznych}

Wyniki badań właściwości mechanicznych (wytrzymałość na rozciąganie oraz kąt gięcia) niejednorodnych złączy spawanych zestawiono w tablicy II. Przeprowadzone badania wykazały, że złącza spawane poddane statycznej próbie rozciągania zawsze ulegały zerwaniu w materiale rodzimym - stal X20. Złącza nr 15, 16, 17 charakteryzowały się jednak wytrzymałością na rozciąganie niższą od wymaganego dla stali X20 minimum, tj. $R_{m}=690 \mathrm{MPa}$. Wynika to z długości czasu wyżarzania złączy w temperaturze $770{ }^{\circ} \mathrm{C}$, co prowadzi do obniżenia właściwości wytrzymałościowych. Wykazano, że złącza po wyżarzaniu w temperaturze $770{ }^{\circ} \mathrm{C}$ niezależnie od czasu wygrzewania, spełniały wymóg właściwego kąta gięcia (tabl. II), natomiast złącze bez obróbki uległo pęknięciu przy kącie mniejszym od wymaganego.

Tablica III. Praca łamania niejednorodnych złączy spawanych Table III. Impact energy for dissimilar welding joints

\begin{tabular}{|c|c|c|}
\hline $\begin{array}{c}\mathrm{Nr} \\
\text { złącza }\end{array}$ & $\begin{array}{c}\text { Miejsce } \\
\text { nacięcia karbu }\end{array}$ & $\begin{array}{c}\text { Praca tamania } \\
\mathrm{KV}_{2}{ }^{*}, \mathrm{~J}\end{array}$ \\
\hline \multirow{4}{*}{8} & SWC - Lico & 96 \\
\cline { 2 - 3 } & Spoina & 7 \\
\cline { 2 - 3 } & SWC - Grań & 134 \\
\hline \multirow{4}{*}{11} & SWC - Lico & 110 \\
\cline { 2 - 3 } & Spoina & 33 \\
\cline { 2 - 3 } & SWC - Grań & 112 \\
\hline \multirow{4}{*}{16} & SWC - Lico & 88 \\
\cline { 2 - 3 } & Spoina & 26 \\
\cline { 2 - 3 } & SWC - Grań & 76 \\
\hline & SWC - Lico & 64 \\
\cline { 2 - 3 } & Spoina & 22 \\
\hline \multirow{4}{*}{17} & SWC - Grań & 95 \\
\cline { 2 - 3 } & SWC - Lico & 65 \\
\cline { 2 - 3 } & Spoina & 24 \\
\hline
\end{tabular}

Tablica II. Właściwości wytrzymałościowe niejednorodnych złączy spawanych

Table II. The strength properties of dissimilar welding joints

\begin{tabular}{|c|c|c|c|c|c|}
\hline \multirow{2}{*}{$\begin{array}{c}\mathrm{Nr} \\
\text { złącza }\end{array}$} & \multicolumn{3}{|c|}{ Próba gięcia } & \multicolumn{2}{|c|}{ Statyczna próba rozciągania } \\
\hline & Miejsce rozciągania & Miejsce pękania & Kąt gięcia & $\mathrm{R}_{\mathrm{m}^{\prime}} \mathrm{MPa}$ & Miejsce zerwania próbki \\
\hline \multirow{2}{*}{8} & Grań & SWC grani & $88^{\circ}$ & \multirow{2}{*}{732} & \multirow{2}{*}{ Materiał rodzimy stal X20 } \\
\hline & Lico & SWC lica & $78^{\circ}$ & & \\
\hline \multirow{2}{*}{11} & Grań & - & $180^{\circ}$ & \multirow{2}{*}{786} & \multirow{2}{*}{ Materiał rodzimy stal X2C } \\
\hline & Lico & - & $180^{\circ}$ & & \\
\hline \multirow{2}{*}{15} & Grań & - & $180^{\circ}$ & \multirow{2}{*}{686} & \multirow{2}{*}{ Materiał rodzimy stal X20 } \\
\hline & Lico & - & $180^{\circ}$ & & \\
\hline \multirow{2}{*}{16} & Grań & - & $180^{\circ}$ & \multirow{2}{*}{663} & \multirow{2}{*}{ Materiał rodzimy stal X20 } \\
\hline & Lico & - & $180^{\circ}$ & & \\
\hline \multirow{2}{*}{17} & Grań & - & $180^{\circ}$ & \multirow{2}{*}{615} & \multirow{2}{*}{ Materiał rodzimy stal $\mathrm{X} 2 \mathrm{C}$} \\
\hline & Lico & - & $180^{\circ}$ & & \\
\hline
\end{tabular}


Przeprowadzone próby udarności badanych złączy (tabl. III) wykazały, że w strefie wpływu ciepła niezależnie od miejsca nacięcia karbu odporność na pękanie badanego złącza była wysoka. Praca łamania spoiny bez obróbki cieplnej wynosiła jednak 7 J. Obróbka cieplna - wyżarzanie w temperaturze $770{ }^{\circ} \mathrm{C}$ przyczyniło się do wzrostu ciągliwości spoiny. Wyżarzanie spoiny przy parametrach $770{ }^{\circ} \mathrm{C} / 1 \mathrm{~h}$ doprowadziło do uzyskania pracy łamania na poziomie $33 \mathrm{~J}$, wyższej niż wymagane minimum. Jak wykazały wcześniejsze badania własne [8], niższa temperatura wyżarzania - temperatura $650^{\circ} \mathrm{C}$ nie gwarantuje uzyskania wymaganej ciągliwości spoiny. Dłuższe czasy wyżarzania w temperaturze $770{ }^{\circ} \mathrm{C}$ przyczyniają się natomiast do obniżenia ciągliwości całego złącza, z tym że dla spoiny uzyskano wyniki na nieakceptowalnym poziomie.

Przykładowe rozkłady twardości niejednorodnych złączy spawanych stali VM12/X20 przedstawiono

a)
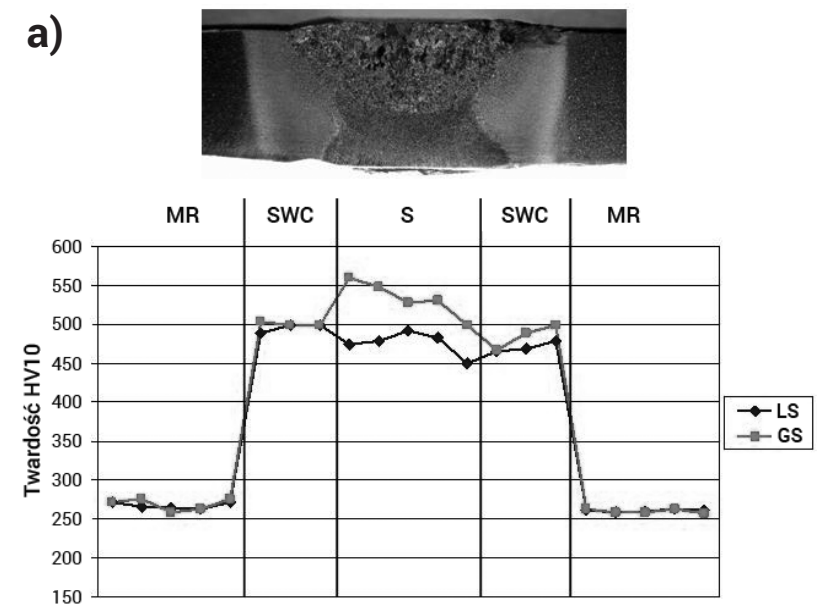

b)
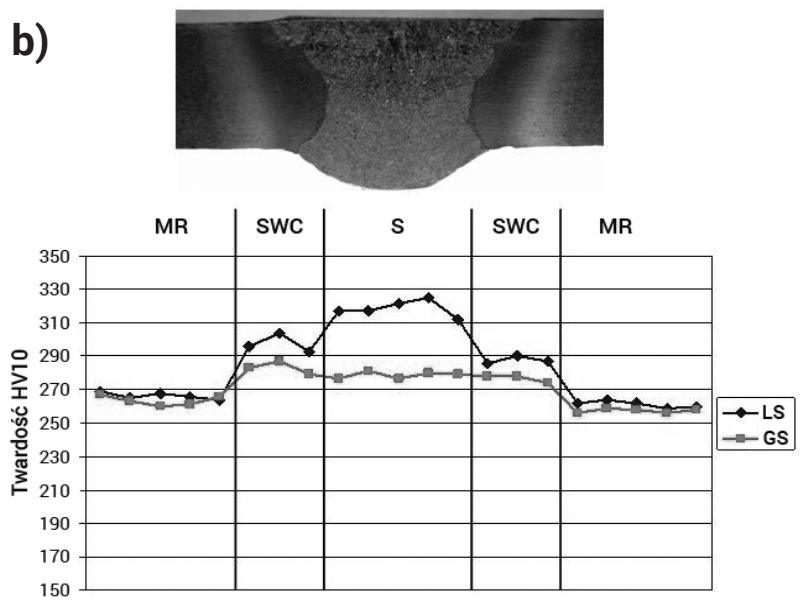

e)
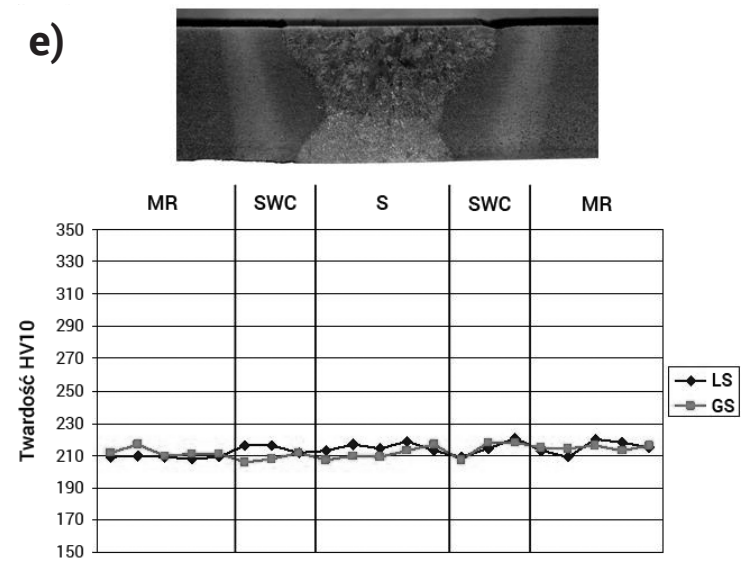

na rysunku 3. Analiza uzyskanych wyników badań wykazała, że złącze bez obróbki cieplnej posiada wysoką, nieakceptowalną twardość na poziomie wynoszącym ok. 500 $\div 550$ HV10. Według [9] złącze o twardości powyżej 350 HV10 charakteryzuje się wysoką skłonnością do pęknięć zimnych. Prawidłowo przeprowadzona obróbka cieplna - wyżarzanie po spawaniu $\left(770{ }^{\circ} \mathrm{C} / 1 \mathrm{~h}\right)$ pozwoliła obniżyć twardość w obrębie złącza spawanego do wartości maksymalnie ok. 320 HV10 oraz zmniejszyć gradient twardości na przekroju złącza.

Dłuższe czasy wygrzewania badanego złącza w temperaturze wyżarzania skutkują znaczącym zanikiem różnic $w$ wartości twardości pomiędzy poszczególnymi strefami złącza (rys. 3c $\div 3 e$ ), prowadząc do wyrównania twardości na przekroju złącza, lecz jednocześnie skutkują dyskwalifikującym spadkiem Rm (tabl. II) czy też ciągliwości (tabl. III).

c)
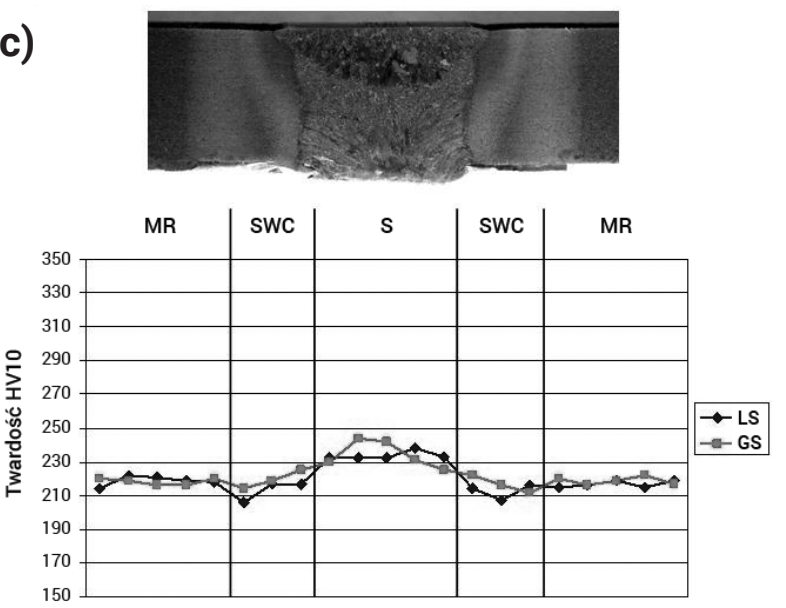

d)
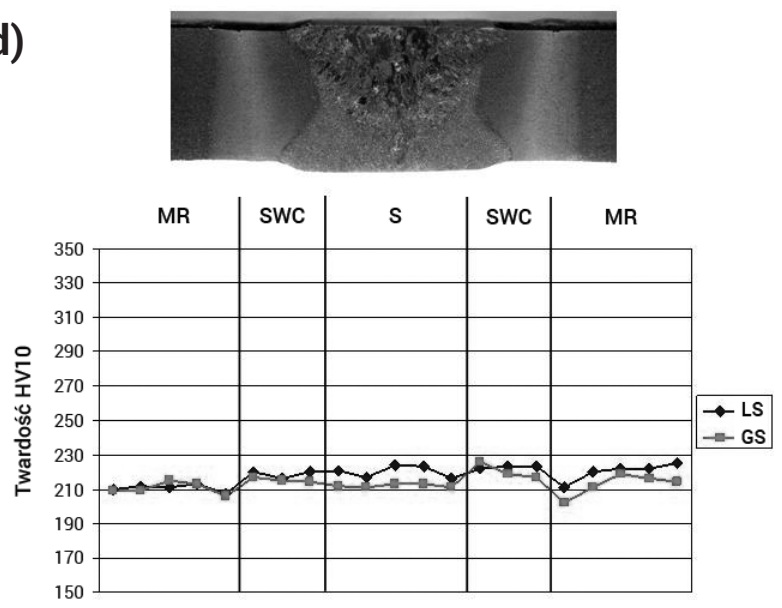

Rys. 3. Rozkład twardości niejednorodnych złączy spawanych stali VM12/X20: a) złącze $\mathrm{Nr} 8$, b) złącze $\mathrm{Nr} 11$, c) złącze $\mathrm{Nr} 15$, d) złącze $\mathrm{Nr}$ 16, e) złącze $\mathrm{Nr}$ 17; MR - materiał rodzimy, SWC - strefa wpływu ciepła, S - spoina, LS - lico spoiny, GS - grań spoiny

Fig. 3. Hardness distribution of dissimilar welding joint of VM12/X20 steel: a) joint No. 8, b) joint No. 11, c) joint No. 15, d) joint No. 16, e) joint No. 17; MR - parent material, SWC - heat affected zone, S - weld, LS - face of weld, GS - root of weld 


\section{Podsumowanie}

Badaniu mikrostruktury i właściwości mechanicznych poddano niejednorodne złącza spawane stali VM12/X20 łączone różnymi materiałami dodatkowymi. Wykonane złącza charakteryzowały się prawidłową budową, bez niezgodności spawalniczych. Kształt spoiny i układ ściegów był prawidłowy. Badania mikrostrukturalne nie wykazały obecności obszarów o nieprawidłowej budowie, a samo złącze charakteryzowało się mikrostrukturą martenzytu odpuszczonego. Obróbka cieplna - jednogodzinne wyżarzanie w temperaturze $770{ }^{\circ} \mathrm{C}$ przyczyniło się do wzrostu ciągliwości spoiny do wartości na poziomie $33 \mathrm{~J}$. Dłuższe czasy wyżarzania w temperaturze $770{ }^{\circ} \mathrm{C}$ przyczyniają się natomiast do obniżenia ciągliwości całego złącza, z tym że dla spoiny uzyskano wyniki na nieakceptowalnym poziomie. Długie czasy wyżarzania prowadzą również do obniżenia $\mathrm{Rm}$ poniżej wymaganego minimum. Obróbka cieplna po spawaniu - wyżarzanie $\left(770{ }^{\circ} \mathrm{C} / 1 \mathrm{~h}\right)$ pozwoliło obniżyć twardość w obrębie złącza spawanego z wartości ok. $500 \div 550{ }^{\circ} \mathrm{C}$ HV10 dla złącza bez obróbki cieplnej do wartości ok. 320 HV10 oraz zmniejszyć gradienty twardości na przekroju złącza. Znaczący zanik różnic w wartości twardości pomiędzy poszczególnymi strefami złącza gwarantują dłuższe czasy wygrzewania badanego złącza w temperaturze wyżarzania, co prowadzi do wyrównania twardości na przekroju złącza.

\section{Literatura}

[1] M. Zeman, S. Błacha: Spawalne martenzytyczne stale żarowytrzymałe nowej generacji, Przegląd Spawalnictwa, Vol. 86, Nr 4, s. 51 $61,2014$.

[2] G. Golański, I. Pietryka, J. Słania, J. Jasak, P. Urbańczyk: Mikrostruktura i właściwości mechaniczne złącza spawanego stali $12 \mathrm{HMF}$ po długotrwałej eksploatacji, Przegląd Spawalnictwa, Vol. 86, Nr 5, s. 49 $\div 53,2014$.

[3] M. Urzynicok, K. Kwieciński, J. Słania: Zastosowanie nowoczesnych metod spawania przy wykonywaniu połączeń doczołowych rur ze stali martenzytycznej P92 (X10CrWMo-

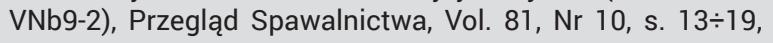
2009.

[4] Y.Y. You, R.K. Shiue, R.H. Shiue, C. Chen: The study of carbon migration in dissimilar welding of the modified $9 \mathrm{Cr}-1 \mathrm{Mo}$ steel,

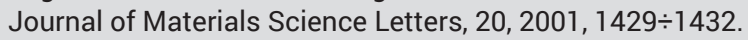

[5] C. Sudha, R. Anand, S. Saroja, M. Vijayalakshmi: Evaluation of concentration dependant diffusion coefficients of carbon in a dissimilar joint of ferritic steels, Transactions of The In- dian Institute of Metals, 63, 4, 2010, 739 $\div 744$.

[6] M. Yamazaki, T. Watanabe, H. Hongo, M. Tabuchi: Creep rupture properties and fracture type of $9 \mathrm{Cr}-1 \mathrm{Mo}-\mathrm{V}-\mathrm{Nb} / 18 \mathrm{Cr}-8 \mathrm{Ni}$ steel

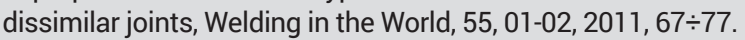

[7] W. Pawełczyk, K. Wojsyk: Własności złączy jednorodnych i niejednorodnych z udziałem stali VM12 i X20CrMoV12-1, Niepublikowany raport - Elektrownia Bełchatów, 2014.

[8] E. Tasak, A. Ziewiec, Spawalność materiałów konstrukcyjnych. Tom 1-Spawalność stali, Wydawnictwo JAK, Kraków, 2009.

[9] K. Wojsyk, G. Golański, J. Jasak, J. Kupczyk: Mechanical properties of dissimilar welding joints made of VM12/X20CrMoV12-1 steels, The 46th International October Conference on Mining and Metallurgy, Bor Lake, Serbia, 2014, 314 $\div 317$. 